Jakub Jankowski (D)

Universidade de Varsóvia jakub.s.jankowski@uw.edu.pl

\title{
Histórias em quadrinhos ${ }^{1}$ traduzidas (e no prelo) para polaco Abordagem histórica e teórica na área dos estudos de tradução
}

\begin{abstract}
Resumo:
Histórias em quadrinhos (HQs) traduzidas (PT-BR $\rightarrow$ PL) e publicadas em polaco contam 14 volumes (álbuns). Da excepcionalidade do meio, bem como da imagem linguística do mundo ( $J O S$ - językowy obraz świata) onde decorre a ação, resultam várias condições que influenciam o texto de chegada e que podem servir como exemplo vivo para formular algumas regras que moldam o texto final no caso dos comics. Pretende-se no presente artigo objetivar a própria experiência empírica do processo de tradução através da abordagem metodológica que combina a introspeção (psicologia cognitiva), teoria de tradução e teoria de comics. A reflexão que nasce desta ligação junta a perspetiva de dois autores (tradutor + pesquisador [na área dos ET e dos comics]) e permite autodefinir, descrever e resolver de uma forma objetivada os maiores problemas tradutológicos que se encontram nas HQs traduzidas.
\end{abstract}

Palavras-chave: histórias em quadrinhos, tradução de comics, JOS, the network, openness, fechamento (closure)

1 No presente artigo sempre que se falar sobre comic books em geral, usar-se-á o nome «comics»; sempre que se falar sobre os livros portugueses, «banda desenhada» (BD), e quando sobre os livros brasileiros, «história(s) em quadrinhos» $[\mathrm{HQ}(\mathrm{s})]$. A motivação para tal decisão é a de referirmos ao nível linguístico realidades diferentes. 


\begin{abstract}
:
Brazilian Comic Books Translated (and Being Currently Translated) into Polish. Historical and Theoretical Approach in the Area of Translation Studies Comic strips (HQs) translated and published in Polish (PT-BR $\rightarrow$ PL) count 14 volumes (albums). Several conditions that influence the target text result from the exceptionality of the medium as well as from the linguistic worldview (JOS - językowy obraz świata) of the story itself, and as such can serve as a living example to formulate some rules that shape the final text in the case of comics. The present article aims to objectify the empirical experience of the translation process through the methodological approach that combines introspection (cognitive psychology), translation theory and comics theory. The reflection that emerges from this connection joins the perspective of two authors (translator + researcher [in the area of TS and comics]) and allows to self-define, describe and solve in an objective way the major translation problem that are found in the translated HQs.
\end{abstract}

Keywords: Histórias em Quadrinhos, translation of comics, JOS, the network, openness, closure

No presente artigo pretendo aprofundar a perspetiva metodológica aceite no texto Banda desenhada portuguesa traduzida para polaco. Abordagem histórica e teórica na área dos estudos de tradução (Jankowski, 2014: 403-415) e processar o material do exemplário das HQs nesses moldes revistos. Como é de prever, os problemas tradutológicos estruturais que se encontram traduzindo HQs serão parecidos aos identificados na BD, mas podemos esperar também que a imagem linguística do mundo (ILM; J[ęzykowy] O[braz]S[wiata]; Gicala, 2018), sobre o qual falam as respetivas HQs, possa proporcionar uma perspetiva que influencie as escolhas tradutológicas numa dada estratégia aceite de modo diferente daquela no caso da BD (quanto à estratégia na ILM, aponto para Hejwowski que propõe «fidelidade» alternativamente à dicotomia «domesticar - exotizar»; 2004: 94). A metodologia aceite para o presente artigo é sobretudo a consequência de uma tentativa de alargar o olhar perante os comics em tradução (tanto histórica como teoricamente. Compreende testar ferramentas novas e úteis não apenas para a análise tradutológica das HQs, mas para os 
comics em geral, e preencher uma das lacunas na chamada história nacional da tradução (português $\rightarrow$ polaco).

\section{História da prática da tradução: o que se traduziu, quem tradu- ziu, em que circunstâncias e contexto sociopolítico?}

O subtítulo em cima faz referência às perguntas que Judith Woodsworth identificou como básicas para este segmento histórico dos Estudos de Tradução (ET) (Woodsworth, 1998/2001: 100-105). Da mesma forma que esta contribuidora para Routledge Encyclopedia of Translation Studies diz que "a «history of histories» has yet to be written" (Woodsworth 1998/2001: 100), também eu apoio a moção dela, mas no que diz respeito aos comics. No caso do par linguístico português-polaco existe uma modesta contribuição minha que cobre esta área no artigo suprareferido (BD: PT-PT $\rightarrow$ PL). O presente artigo tem como um dos objetivos alargar o estudo para as HQs (PT-BR $\rightarrow$ PL). Tendo em conta a peculiaridade do estudo que proponho (autoanálise empírica), nos dois casos a história nacional faz referência unilateral $(\mathrm{PT}-\mathrm{PT} / \mathrm{PT}-\mathrm{BR} \rightarrow \mathrm{PL})^{2}$.

$\mathrm{Na}$ parte das referências bibliográficas (Bibliografia activa) apresento a lista completa das HQs publicadas na Polónia, o que responderá às perguntas «o que se traduziu?» e «quem traduziu?». Aqui, por sua vez, tentarei desenvolver a questão das circunstâncias e do contexto nos quais na Polónia são publicadas HQs, o que proporcionará uma visão da dinâmica editorial no quadro polissistémico

${ }^{2}$ Efetivamente, na data da entrega do presente artigo são-me desconhecidos casos de tradução de BD/HQ: $\mathrm{PL} \rightarrow$ PT-PT/PT-BR, a não serem adaptações em BD/HQ da obra de Henryk Sienkiewicz (veja mais em: Birek 2018), mas neste caso trata-se de adaptações das obras do escritor polaco (provavelmente com base nas traduções de prosa existentes em PT-PT ou em PT-BR) e não de traduções diretas dos comics polacos adaptados da obra de Sienkiewicz e só depois traduzidos para BDs/HQs; o caso em si não deixa de ser bastante interessante, tendo em conta que a adaptação também pode ser vista como um tipo de tradução, nomeadamente, a tradução intersemiótica (veja mais em: Gottlieb 2007 e Kaźmierczak 2017). 
entre o Brasil e a Polónia aquando dos comics traduzidos. Na relação Polónia $\leftrightarrow$ Brasil podemos falar sobre o quadro semiperiférico (Pięta 2013: 21-33) ${ }^{3}$.

Em 2004, quanto à BD, poder-se-ia ter indicado tanto álbuns como histórias curtas presentes no mercado polaco (na altura todas as traduções eram feitas diretamente do português, salvo as curtas da Sónia Oliveira). Se medirmos a dinâmica da publicação apenas pelos álbuns de BD publicados na Polónia entre 2008-2013 (anos que abrangem o meu artigo de 2014) e anos posteriores (2015-2019; livros publicados e no prelo; neste período existe ainda uma BD traduzida indiretamente, do inglês - Electronic memory. Man:Plus de André Lima Araújo), nesses 12 anos editoriais contamos com 13 livros (traduções diretas) o que dá uma média de 1,083 livro por ano. A primeira HQ na Polónia, traduzida diretamente do português (a primeira dos autores brasileiros, Daytripper, mas traduzida do inglês, foi lançada em 2012) e publicada em álbum (existe ainda uma curta de Dantas "Zabili Indianina Galdina/Mataram o Índio Galdino”) surgiu, por sua vez, em 2016. Contando com os livros confirmados para publicação este ano (2019), temos 16 álbuns o que dividindo pelos anos editoriais (4) resulta numa média consideravelmente superior à portuguesa, de 4 por ano.

Há várias razões que possivelmente tiveram influência no cenário que observamos hoje em dia na Polónia: o Brasil, país convidado especial da Feira do Livro 2013 em Frankfurt (entre 70 autores encontramos 7 quadrinhistas) ${ }^{4}$; lançamento do programa brasileiro de apoio à tradução e à edição em 2012 (Ministério da Cultura/Fundação

${ }^{3}$ Obviamente o estudo de Pięta tem em foco PT-PT, mas entre os estudos citados pela autora, não se encontram referências ao PT-BR nos grupos centrais (ou seja, nos hypercentral e central; Heilbron, 2010).

${ }^{4}$ Vale a pena citar aqui a opinião que encontramos no ípisilon: "É a segunda vez que o Brasil é o país convidado da Feira do Livro de Frankfurt. Foi-o em 1994, e a organização não quer repetir os erros que cometeu há 19 anos. Nessa altura, houve muita caipirinha, mulatas e samba, mas pouca repercussão literária. Não houve, por exemplo, continuidade na tradução de obras brasileiras internacionalmente. E se os autores não são traduzidos, não são lidos" (Coutinho, 2013: página web). 
da Biblioteca Nacional); autores-embaixadores (irmãos Moon e Bá nos EUA; Marcello Quintanilha ${ }^{5}$ em Espanha e França, André Diniz em Portugal, Marcelo D'Salette - vencedor do prémio Eisner, chamado "Óscar dos Quadrinhos" nos EUA) que aumentam a visibilidade dos autores brasileiros; cooperação direta Polónia-Portugal (entre as editoras portuguesas Polvo - que publica a coleção Romance Gráfico Brasileiro - e Kingpin Comis - que tem no catálogo autores brasileiros - com a polaca Timof Comics; cooperação dos festivais de BD de Beja - que tem sempre convidados brasileiros - e de Varsóvia; presença brasileira no festival de Angoulême (o maior festival europeu de comics onde aparece sempre a delegação polaca); fundação da editora polaca Mandioca que aposta nos autores brasileiros; mercado polaco em crescimento e à procura de novos autores.

Uma grande vantagem no contexto suprareferido é o facto de no mercado editorial polaco, que tem uma oferta em crescimento, se

${ }^{5}$ Tendo em conta que na parte prática irei falar sobre dois livros deste autor, deixo aqui algumas informações sobre Marcello Quintanilha: “(...) nasceu em 1971, em Niterói. Atualmente mora em Barcelona. Autodidata, tornou-se quadrinista profissional ainda adolescente, nos anos 1980, desenhando gibis de terror e artes marciais para a editora Bloch. Nos anos 1990, passou a publicar seus quadrinhos em revistas como a General, General Visão, Nervos de Aço, Metal Pesado, Zé Pereira e a Heavy Metal. Em 1991, foi premiado no Salão do Humor de Ribeirão Preto. Ainda nesse ano foi premiado na $1^{\text {a }}$ Bienal de Quadrinhos do Rio de Janeiro. E voltou a ser premiado na segunda edição da Bienal, em 1993. Em 1999, foi premiado no Salão Carioca de Humor. Também em 1999, pela editora Conrad, lançou seu primeiro livro de quadrinhos: Fealdade de Fabiano Gorilla. Nesse momento, Marcello Quintanilha ainda assinava "Marcello Gaú". A Conrad publicou mais dois álbuns dele: Sábado dos Meus Amores (2009) e Almas Públicas (2011). TUNGSTÊNIO foi lançado pela Veneta em 2014. E logo depois na Espanha, França, Alemanha, Itália, Polônia... Um sucesso internacional que rendeu a Quintanilha diversos prêmios, incluindo o mais importante: o Angoulême. Em 2018 a adaptação do livro estreou nos cinemas brasileiros, dirigida por Heitor Dhalia, com uma estética bastante fiel ao livro. TALCO DE VIDRO foi lançado em 2015. Outro grande sucesso de vendas e de crítica. Em 2016 lançou HINÁRIO NACIONAL, premiado com um Jabuti. Seu livro mais recente é TODOS OS SANTOS (Veneta, 2018)". (Veneta: www). 
procurarem novos autores cada vez mais, sendo por isso inestimável o papel que na introdução das HQs desempenham todos os intermediários indicados acima.

\section{História da teoria da tradução: o que dizem os tradutores sobre o seu ofício e que tipo de conselhos/dicas eles dão?}

Tal como o subtítulo anterior, também este faz referência à entrada enciclopédica sobre a história da tradução de Judith Woodsworth. De todas as questões que Woodsworth abrange no âmbito da história da teoria da tradução, sublinho na minha abordagem duas que se encaixam na autoreflexão empírica (tradutor + pesquisador $=$ unidade) que pretendo juntar com as perspetivas teóricas dos ET (entre outros com ILM; processo da tomada de decisões de Levý; Pentathlon Principle de Peter Low) e dos estudos de comics (p.ex. the network de Miodrag, Groensteen e Cohn, closure de McCloud, openness de Ahmed).

Um dos maiores mistérios na área dos estudos de tradução é a chamada "caixa negra do tradutor", ou seja, lugar onde ocorrem todas as decisões tradutológicas. Pode-se tentar estudá-la através de aparelhos técnicos (p.ex. ver através dos eye-tracking devices como funcionam os chamados reading patterns no caso da tradução dos comics e como influenciam o reading experience ${ }^{6}$ ), mas é um passo na minha reflexão sobre os processos de tradução que será posterior a este (ou seja, não abrangido no presente estudo) que quero propor aqui: recorrer à introspeção (psicologia experimental cognitiva) e, em sequência, objetivizar os resultados obtidos, fundamentando a reflexão própria sobre o processo e escolhas tomadas aquando do exercício de tradução, pela teoria híbrida $(\mathrm{BD}+\mathrm{ET})$. Pretendo assim voltar à maneira como as ideias eram expressas pelos tradutores no primeiro dos 4 períodos que

${ }^{6}$ Sobre esta correlação entre os padrões de leitura definidos para várias estruturas narrativas de BD e a experiência de leitura que provocam, falei na conferência da Associação dos Cognitivistas em Poznań (Setembro 2018); trata-se de perceber que os reading patterns que encontramos na teoria de BD limitam o reading experience que podemos garantir a nós próprios para sentir maior prazer da leitura. 
identificou Goerge Steiner em After Babel no que diz respeito à escrita sobre a teoria, a prática e a história da tradução. Steiner escreve sobre este período (que se estende desde Cícero e Horácio até Alexander Fraser Tytler) o seguinte: "the main characteristic of this first period is that of immediate empirical focus" (Steiner, 1975: 236). Recorrendo à introspeção, ou seja, a uma atividade que possibilita ao sujeito observar os seus próprios estados mentais e ganhar sobre eles consciência, e onde se pode destacar conteúdos mentais passíveis de introspeção tais como as intenções, as emoções e o conteúdo do pensamento em geral (conceitos, raciocínios, associações de ideias), tento abrir a minha própria "caixa negra" o que proporcionará neste artigo resultados passíveis de processamentos teóricos consequentes. Trata-se de um raciocínio e ação desenvolvidos assim como proposto, p.ex., no estudo de Leal Ferreira e Castro, onde o autor diz que “(...) neste exercício (...) o próprio observador viria a se transformar em um instrumento científico por meio de um processo de treinamento específico" (Leal Ferreira, Castro: www).

Ao mesmo tempo tenho plena consciência da crítica deste método na área dos estudos da psicologia experimental (Almada, 2008: 75-82) e da insuficiência dela como um método científico. Como nos explica Piotr Gąsowski (ao falar sobre a poética cognitiva dos comics), por um lado, parece lógico que ninguém saberá melhor o que se passa na nossa cabeça do que nós próprios, mas por outro lado é também lógico que a introspeção tem limites - não permite desencobrir todo o inconsciente e é difícil discernir o falso do verdadeiro (Gąsowski, 2016: 38). No entanto, creio que se se juntar à introspeção ferramentas teóricas objetivizantes do âmbito das teorias de BD e dos ET, poder-se-á com base na experiência pessoal formular uma teoria de tradução de BD reforçada teoricamente, o que, por enquanto, não existe. Assim nascerá um enquadramento mais desenvolvido, fundamentado e aprofundado do que simples dicas como, por exemplo, as famosas cinco regras que D. Duarte formulou no Leal Conselheiro (para detalhes, veja: Amorim Machado e Martins, 2010; Tavares de Pinho, 1993). 


\section{Teoria de BD e Teoria de tradução na prática}

Nesta secção do artigo pretendo comentar casos escolhidos de traduções minhas (elemento introspetivo apresentado forçosamente apenas através dos resultados do exercício analítico) das HQs para o polaco. Para tal, escolhi (na função do tradutor-perito na área da cultura e língua portuguesas) questões de 2 livros do mesmo autor publicados na Polónia, ou seja, de Wolfram e Modlitewnik narodowy de Marcello Quintanilha.

\section{Wolfram (Tungstênio)}

Qualquer leitor confrontado com este livro logo se aperceberá que uma simples leitura sequencial no modelo $z$-path (leitura esquerda $\rightarrow$ direita / cima $\rightarrow$ baixo; McCloud, 2006: 32) ou seguindo ścieżka [vereda] (uma linha de leitura que traçamos ao ler sequências numa página; Gąsowski, 2016: 148-174) não permitirá experienciar na totalidade a narrativa proposta por Quintanilha. Closure [fechamento] (a atividade de preencher tudo o que não vemos para poder perceber, p.ex., uma sequência; McCloud, 1993: 60-93) mccloudeano tem de funcionar aqui em toda a network [rede] (totalidade de painéis que criam sequências narrativas lineares e ligações não lineares; Miodrag, 2103: 108-141), ou seja, não apenas para possibilitar a ligação de painéis vizinhos. Na network as ligações podem ser tanto lineares como translineares, fazendo com que virtualmente cada painel possa reagir significativamente com o outro. Esta possibilidade de leitura translinear foi sublinhada tanto por Miodrag, como por Cohn e Groensteen (Miodrag, 2013: $124,128,134)$. Groensteen propõe falar tanto sobre ligações diretas entre elementos vizinhos numa estrutura linear (restrained arthrology), como também sobre interação translinear entre elementos não vizinhos (general arthrology) (Groensteen, 2007: 103-158). A composição de Tungstênio é uma verdadeira rede de ligações onde o leitor/tradutor tem de ter ainda em conta o texto fragmentado, cujas partes têm de se enquadrar uma na outra, mesmo que estejam separadas por várias páginas numa sequência entrecortada. A necessidade de ligar sequências menores que aparecem entrecortadas por outras sequências menores, 
faz com que o tradutor/leitor tenha de quebrar várias vezes a leitura na ordem z-path, bem como sair de uma única linha de ścieżka [vereda] (estudando a possibilidade de escolher outras veredas) para poder criar o seu próprio reading experience (a procura desta experiência é puramente introspetiva). O leitor/tradutor tem de voltar várias vezes a alguns fragmentos da narrativa e seguir em frente, para se aperceber de todos os truques sequenciais usados por Quintanilha. Só assim será possível traduzir corretamente os textos aparentemente elípticos que aparecem neste livro.

Embora Neil Cohn, ao criticar a ideia de Groensteen da existência de ligações lineares e translineares entre todos os painéis de um dado livro, diga que decifrar uma estrutura assim concebida seria demasiado para as possibilidades cognitivas do leitor (Cohn apud Miodrag 2013: 129), Tungstênio parece um exercício de ideias groensteeneanas posto em prática e ainda por cima legível e bem conseguido (veja: Fig. 1). No caso do modo como a estrutura da HQ em questão se transpõe às partes diretamente traduzidas, é interessante observar que um dos críticos, Dominik Szcześniak, escreveu na crítica de Wolfram que esta realização da network "à primeira vista parece uma série de erros caóticos do tradutor e do editor, mas, na verdade, compreende um truque bem conseguido de refletir as ideias do autor" (Scześniak, 2016: www). As palavras de Szcześniak comprovam que a estrutura translinear deste livro, tem uma ligação direta com o texto entrecortado que tem de ser traduzido, refletindo a estrutura narrativa distorcida original.

\section{Modlitewnik Narodowy (Hinário Nacional)}

É uma coletânea de histórias curtas nas quais Marcello Quintanilha tenta ligar o texto e a imagem de forma pouco óbvia, escolhendo quase sempre a categoria que em McCloud se situa entre parallel e interdependent, então as duas que compreendem uma desligação (várias vezes aparente) entre as unidades textual e pictórica dum dado painel (McCloud, 2006: 137-138). Closure ao nível da ligação texto-imagem realiza-se aqui de um modo muito exigente, pois a imagem não ajuda na compreensão do que se diz (veja: Fig. 2). Mas este mesmo closure 
também é exigente na recriação das sequências que várias vezes recorrem a transições tipo subject-to-subject, scene-to-scene, aspect-to-aspect ou non-sequitur (McCloud, 1992: 74), então a todo o tipo que não recrie sequências fáceis e que possam ajudar a compreender os acontecimentos (veja: Fig. 3). Quintanilha aposta aqui na desligação ao nível estrutural o que faz com que crie uma obra muito aberta às interpretações e extremamente passível de provocar erros na leitura dos significados. No caso de um simples leitor, o que pode sofrer é o reading experience, mas no caso do leitor/tradutor, esta questão estrutural pode levar a erros tradutológicos. Enquanto que o leitor pode fazer leituras seguintes e finalmente perceber corretamente a intenção do autor, o tradutor não tem tanto tempo para tomar decisões (na maioria dos casos são os prazos de entrega da tradução que o impossibilitam), daí a possibilidade de cometer um erro ser maior. O que Ahmed chama openness (abertura), ligando a ideia de Eco de opera aperta com as caraterísticas estruturais dos comics, funciona neste caso como um obstáculo interpretativo para o tradutor (Ahmed, 2016: 3-22; 150-167).

\section{Conclusões}

A escolha de dificuldades supramencionada é subjetiva (introspetiva) e ao mesmo tempo parcial. As duas HQs referidas apresentam mais questões que poderão surgir na autoreflexão tradutológica introspetiva e que também exigirão uma óbvia objetivação teórica. Por causa do limite de espaço optei apenas por sugerir como se pode objetivar as interpretações pessoais, em vez de as expor detalhadamente, e de apontar parcialmente nesta secção de conclusões os casos de outros livros.

Por exemplo em Favela w kadrze (Morro da Favela) a linguagem que os protagonistas usam (a necessária estilização linguística nunca será consensual nem cronológica, nem contextualmente) e o estilo gráfico do autor (o possível reading experience desafia as capacidades dos leitores que decifram o significado da tensão originado entre o dito e o desenhado segundo o mecanismo de tensões hatfieldeano art of tensions; Hatfield 2005: 32-67; uma das possíveis ferramentas que o tradutor tem para não confundir os protagonistas e traduzir 
adequadamente as falas, é close viewing, isto é, close reading adaptado para uma análise semiótica dos comics; Jankowski, 2011) dificultam a tarefa do tradutor. Em Kocia skórka. Historia samby (Couro de gato. Uma história do samba) é a narrativa elíptica e obscura que exige um grau de closure máximo (interno e externo; o segundo compreende a recorrência a vários paratextos), mas também o elemento musical é exigente quanto às escolhas tradutológicas (para o resolver é preciso recorrer, mesmo que vagamente, às regras da tradução musical de Peter Low conhecidas como «O Princípio do Pentatlo» [The Pentathlon Principle]; Low 2017). Angola Janga. Opowieść z Palmares (Angola Janga: Uma história de Palmares) e Banda dwóch (Bando de dois) proporcionam uma visão pormenorizada da realidade brasileira, respetivamente de mocambos e cangaço, dois fenómenos que trazem consigo muitas peculiaridades terminológicas que têm de ser refletidas no texto de chegada. No caso de Bando de dois pode-se ainda recorrer à ideia de iconicidade na tradução (Kubaszczyk, 2016: 19-124) que possibilitará a tradução do título conservando o som do título original, pois Banda dwóch recorre a sons parecidos ao título original. Raramente é possível aproximar os textos de chegada e partida a este nível.

Creio que juntando os espaços das perguntas de Woodsworth com os componentes teóricos dos ET e dos estudos de comics se consegue criar uma perspetiva verdadeiramente interdisciplinar. Nascem, desta forma, alicerces de um objeto novo de estudo, que não pertence a ninguém unicamente (não só aos ET, nem só aos estudos de comics), e cujo valor não se dilui por pertencer indiscriminadamente a todos, pois pertence a alguns cuidadosamente escolhidos (apenas duas áreas teóricas). A reflexão aqui proposta prova que as áreas dos ET, tal como as definidas por Holmes (1972/2000: 172-185) têm de ser vistas como abertas a influências externas e, sendo de caráter circular entre si (veja-se as reinterpretações do esquema de Toury baseado na classificação de Holmes em: Brzozowski, 2011: 18; Albin, 2017: 127) garantem um olhar construtivo e objetivado para a reflexão tradutológica introspetiva.

Tendo em conta o suprareferido, creio que aceitando as perspetivas indicadas se pode juntar as dimensões sociológica, psicológica 
e linguística de tradução (Hejwowski, 2015: 34) e abordar com respeito a ILM criada nos referidos livros para a recriar com fidelidade.

\section{Referências bibliográficas}

Bibliografia ativa (histórias em quadrinhos) [lista completa das HQs publicadas/no prelo na Polónia]:

\section{Em livro:}

BEYRUTH, D. (arg. e des.) (2019), Banda dwóch, trad. J. Jankowski, Timof Comics, Warszawa [título original: Bando de dois (2010), Zarabatana Books, Campinas].

BORGES, G. (des.), PETER, C. (arg.) (2017), Ptatki, [muda] Timof Comics, Warszawa [título original: Pétalas (2015), Jupati Books/Tambor Quadrinhos, Nova Iguaçu].

CASAL, S. (arg. e des.), BRUNSTEIN, A. (arg.) (2019), Skazaniec 666, trad. J. Jankowski, Mandioca, Warszawa [título original: Prontuário $666-O s$ Anos de Cárcere de Zé do Caixão (2008), Conrad, São Paulo].

DAMASCENO, E. (arg. e des.), GARROCHO, L.F. (arg. e des.) [no prelo], Chiral, trad. J. Jankowski, Timof Comics, Warszawa [título original: Quiral (2015), Mino, São Paulo].

DINIZ, A. (arg. e des.), HORA, M. (fotos) (2017), Favela w kadrze, trad. J. Jankowski, Mandioca, Warszawa [título original: Morro da Favela (2011), Leya/Barba Negra, São Paulo].

DINIZ, A. (arg.), FERREIRA, L. (des.) (2019), Tropikalny Olimp, trad. M. Cichy, Mandioca, Warszawa [título original: Olimpo tropical (2017), Marsupial Editora, Nova Iguaçu].

D’SALETE, M. (arg. e des.) (2019), Angola Janga. Opowieść z Palmares, trad. J. Jankowski, Timof Comics, Warszawa [título original: Angola Janga. Uma história de Palmares (2017), Veneta, São Paulo].

GRAMPÁ, R. (arg. e des.) (2018), Mesmo Delivery, trad. J. Drewnowski [via inglês], Bum Projekt, Warszawa, [título original: Mesmo Delivery (2010), Dark Horse Comics, Milwaukie].

KING, M. (arg. e des.) (2019), 9 godzin, trad. J. Jankowski, Mandioca, Warszawa [título original: 9 horas (2015), edição autoral]. 
MARQUES, M. P. (arg.), MORAIS MARTINS, T. (arg. e des.) (2017), Syrena z Monguaguá, trad. J. Jankowski, Timof Comics, Warszawa [título original: A Sereia de Monguaguá (2016), Veneta, São Paulo].

MOON, F. (arg. e des.), BÁ, G. (arg.) (2012), Daytripper. Dzień po dniu, trad. T. Sidorkiewicz (via inglês), Mucha Comics [título original: Daytripper (2011), DC/Vertigo, NY].

NUNES, F. (arg. e des.) (2017), Dodo, trad. J. Jankowski, Timof Comics, Warszawa [título original: Dodô (2015), Independente, São Paulo].

PATATI, C. (arg.), SANCHEZ, J. (des.) (2018), Kocia skórka. Historia samby, trad. J. Jankowski, K. Sajdakowska, M. Cichy, Mandioca, Warszawa [título original: Couro de gato. Uma história do samba (2017), Veneta, São Paulo].

PETRECA, G. (2018), Ye, trad. M. Cichy, Mandioca, Warszawa [título original: $Y e$ (2016), Veneta, São Paulo].

QUINTANILHA, M. (arg. e des.) (2018), Modlitewnik narodowy, trad. J. Jankowski, Timof Comics, Warszawa [título original: Hinário nacional (2016), Veneta, São Paulo].

QUINTANILHA, M. (arg. e des.) (2016), Wolfram, trad. J. Jankowski, Timof Comics, Warszawa [título original: Tungstênio (2014), Veneta, São Paulo]. SOUTO, T. (arg. e des.) (2019), Labirynt, trad. M. Cichy, Mandioca, Warszawa [título original: Labirinto (2017), Mino, São Paulo.

\section{Curtas:}

DANTAS (arg. e des.) (2009), "Zabili Indianina Galdina”, trad. J. Jankowski, Ziniol, 6, pp. 67-72 [título original: Mataram o Índio Galdino].

\section{Bibliografia passiva:}

ALBIN, J. (2017), "Przekładoznawstwo - nowa dyscyplina naukowa" em: Sarna, M. (ed.), Polska iberystyka, Wydawnictwo Naukowe Uniwersytetu Pedagogicznego, Kraków, pp. 121-134.

ALMADA, L. (2008), "Psicologia como ciência: comportamento, introspecção e consciência", Revista AdVerbum, 3(1), Limeira, pp. 68-85.

AMORIM MACHADO, C., MARTINS, MARCIA A. P. (2010), "Revendo o cânone hegemônico da história das teorias de tradução: o pioneirismo de 
d. Duarte, rei de Portugal", Cadernos de Tradução, 1(25), Florianópolis, pp. 9-28, https://doi.org/10.5007/2175-7968.2010v1n25p9.

BIREK, W. (2018), Henryk Sienkiewicz w obrazkach, Fundacja Instytut Kultury Popularnej, Poznań.

BRZOZOWSKI, J. (2011), Stanąć po stronie thumacza. Zarys poetyki opisowej przekładu, Wydawnictwo Uniwersytetu Jagiellońskiego, Kraków.

COUTINHO, I. (2013), "Brasil, um país de muitas vozes na Feira do Livro de Frankfurt?" [on-line] https://www.publico.pt/2013/10/09/jornal/ brasil-um-pais-de-muitas-vozes-na-feira-do-livro-de-frankfurt-27214856 $-11.01 .2019$.

GĄSOWSKI, P. (2016), Wprowadzenie do kognitywnej poetyki komiksu, Fundacja Instytut Kultury Popularnej, Poznań.

GICALA, A. (2018), Przektadanie obrazu świata. Językowy obraz świata w przektadzie artystycznym, Universitas, Kraków.

GOTTLIEB, H. (2007), "Multidimensional Translation: Semantics Turned Semiotics" em: Nauert, S., Gerzymisch-Arbogast, H. (eds.), Proceedings of the Marie Curie Euroconferences MuTra: Challenges of Multidimensional Translation (EU High Level Scientific Conference Series), pp. 1-29. [on-line] https://www.euroconferences.info/proceedings/2005_Proceedings/2005_Gottlieb_Henrik.pdf - 11.01.2019.

GROENSTEEN, T. (2007), The System of Comics, trad. de francês por B. Beaty e N. Nguyen, University Press of Mississippi, Jackson.

HATTFIELD, C. (2005), Alternative Comics: An Emerging Literature, University Press of Mississippi, Jackson.

HEILBRON, J. (2010), "Structure and Dynamics of the World-System of Translations", [on-line] https://ddd.uab.cat/pub/1611/1611_ a2015n9/1611_a2015n9a4/Heilbron.pdf - 13.01.2019.

HEJWOWSKI, K. (2004), Kognitywno-komunikacyjna teoria przekładu, Wydawnictwo Naukowe PWN, Warszawa.

HEJWOWSKI, K. (2015), Iluzja przekładu, Wydawnictwo Naukowe Śląsk/ Stowarzyszenie Inicjatyw Wydawniczych, Katowice.

HOLMES, J. (1972/2000), "The name and nature of translation studies" em: Venuti, L. (ed.), The Transaltion Reader Studies, pp. 172-185 [versão pdf].

JANKOWSKI, J. (2011), A imagem da palavra na banda desenhada e as suas implicações na leitura, tese de doutoramento orientada pela profa. G. Grudzińska, Universidade de Varsóvia. 
JANKOWSKI, J. (2014), "Banda desenhada portuguesa traduzida para polaco. Abordagem histórica e teórica na área dos estudos de tradução", Studia Iberystyczne, 13, pp. 403-415, https://doi.org/10.12797/SI.13.2014.13.31. KAŹMIERCZAK, M. (2017), "Od przekładu intersemiotycznego do intersemiotycznych aspektów thumaczenia”, Przektadaniec, 34, pp. 7-35, https:// doi.org/10.4467/16891864PC.17.001.8207.

KUBASZCZYK, J. (2016), Faktura oryginatu i przekładu. O przektadzie tekstów literackich, Wydawnictwo Naukowe PWN, Warszawa.

LEAL FERREIRA, A. A., CASTRO, F. S., "Técnicas de si e a introspeção experimental: uma possível linha de trabalhos históricos", [on-line] http:// www.hcte.ufrj.br/downloads/sh/sh9/SH/trabalhos\%20orais\%20completos/ TECNICAS-DE-SI.pdf - 13.01.2019.

LIMA ARAÚJO, A. (2017), Electronic memory. Man: Plus, trad. B. Czartoryski, Timof Comics, Warszawa.

LOW, P. (2016), Translating Song: Lyrics and Texts, Routledge, New York.

MCCLOUD, S. (1993), Understanding Comics, Harper, New York.

MCCLOUD, S. (2006), Making Comics, Harper, New York.

MIODRAG, H. (2013), Comics and Language, University Press of Mississippi, Jackson.

PIĘTA-CÂNDIDO, H. (2013), Entre periferias. Contributo para a história externa da tradução da Literatura polaca em portugal (1855-2010), tese de doutoramento orientada pelos professores doutores Joăo de Almeida Flor e Teresa Menano Seruya, Universidade de Lisboa, Lisboa.

STEINER, G. (1976), After Babel. Aspects of Language and Translation, Oxford University Press, London-New York.

SZCZEŚNIAK, D. (2016), “«Wolfram» - Quintanilha”, [on-line] http://ziniol. blogspot.com/2016/08/wolfram-quintanilha.html - 12.01.2019.

TAVARES DE PINHO, S. (1993), "O triplo código do tradutor de Latim: do leal conselheiro aos nossos dias", Mathesis, 2, Universidade Católica Portuguesa, Viseu, pp. 37-46.

WOODSWORTH, J. (1998/2001), "History of Translation" em: Baker, M. (ed.), Routledge Encyclopedia of Translation, pp. 100-105 [versão pdf].

VENETA, [on-line] https://veneta.com.br/autores/marcello-quintanilha/ -6.04 .2019 . 
Anexo: exemplos das HQs referidas
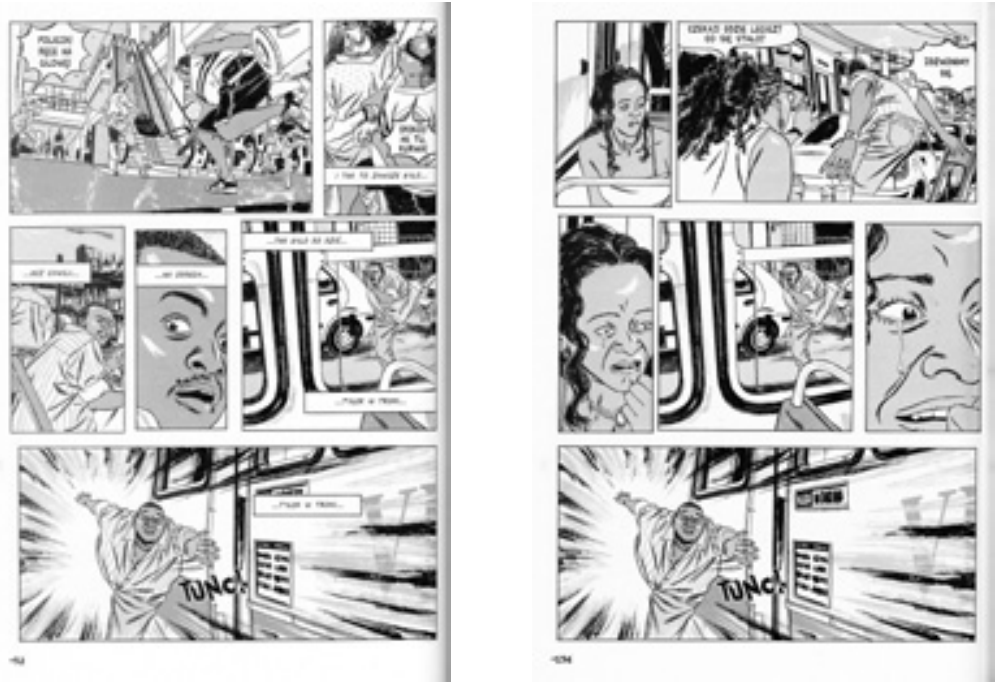

Fig. 1: Uma sequência cortada em Wolfram que se completa parcialmente entre p. 52 e p. 136 (exemplo de funcionamento da network)

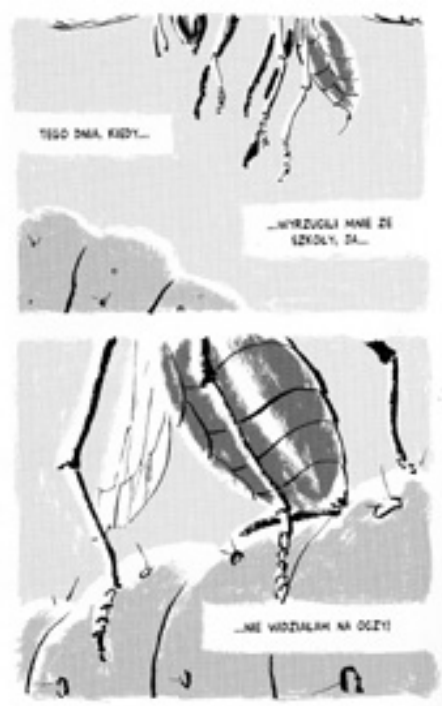

Fig. 2: ligação texto-imagem parallel/ interdependant em Modlitewnik Narodowy - exemplo de closure exigente 

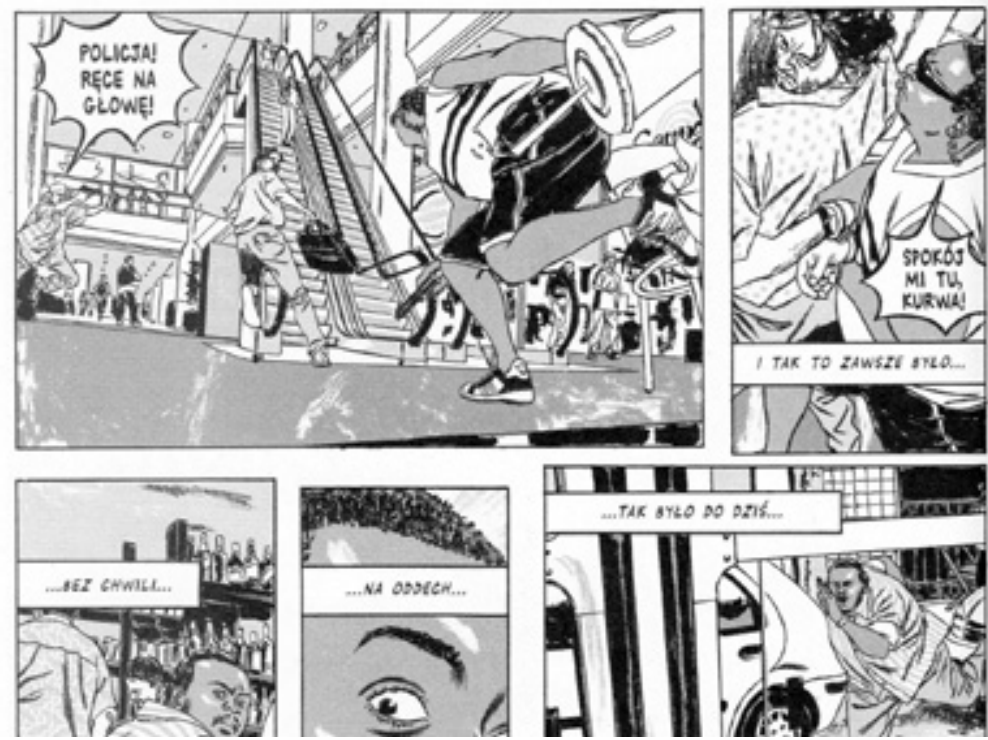

Fig. 3: transição entre vinhetas (de toda a página) em Modlitewnik Narodowy exemplo de um closure exigente na sequência narrativa 